\title{
Wild Fragaria vesca L. fruits: a rich source of bioactive phytochemicals $\uparrow$
}

\author{
Maria Inês Dias, a,b,c Lillian Barros, ${ }^{\text {a,d }}$ Patricia Morales, ${ }^{c}$ Montaña Cámara, ${ }^{c}$ \\ Maria José Alves, ${ }^{e}$ M. Beatriz P. P. Oliveira, ${ }^{b}$ Celestino Santos-Buelga ${ }^{f}$ and \\ Isabel C. F. R. Ferreira*a
}

Received 12th July 2016, Accepted 5th October 2016

DOI: $10.1039 / c 6 f o 01042 c$

www.rsc.org/foodfunction

\begin{abstract}
Wild Fragaria vesca L. fruits were studied regarding nutritional and phytochemical compounds, and also antioxidant, antibacterial and biofilm formation inhibition activities. The fruits are good sources of carbohydrates (e.g., sucrose), soluble dietary fiber and polyunsaturated fatty acids, mainly linoleic and linolenic acids, as well as other components such as citric and succinic acids, and vitamins $B_{9}$ and $E$ (mainly $\gamma$-tocopherol). Significant amounts of soluble sugars, citric acid and some amounts of ascorbic acid, vitamins $B_{9}$ and $E$ (only $\alpha$-tocopherol) were found also in the infusions. The hydromethanolic extracts revealed higher amounts of phenolic compounds, mainly ellagic acid derivatives and dihydroflavonol taxifolin-3-O-arabinofuranoside. Consistently, these extracts also showed higher antioxidant and antibacterial activities than the infusions, and were able to inhibit the formation of bacterial biofilms. Despite the lower content of bioactive compounds in the infusions compared to the fruits, both forms could be potentially applied in functional foods and/or nutraceuticals/pharmaceutical formulations.
\end{abstract}

\section{Introduction}

Fruits are raw materials that can be used for food, either as edible products or as culinary ingredients, medicinal use or ornamental and aesthetic purposes. They are genetically very diverse and play a major role in modern society and economy. Fruits are not only an important component of traditional food, but are also central to healthy diets of the modern urban population. ${ }^{1-3}$ The consumption of fruits is largely widespread throughout the world, being the basis of most diets, not only due to their nutritional characteristics, but also due to the nutraceutical potential that they possess. ${ }^{4}$ Furthermore, there is an intensifying search for new sources of natural com-

\footnotetext{
${ }^{a}$ Mountain Research Centre (CIMO), ESA, Polytechnic Institute of Bragança, Campus de Santa Apolónia, 1172, 5300-253 Braganç, Portugal. E-mail: iferreira@ipb.pt; Fax: +351273 325405; Tel: +351273 303219 ${ }^{b}$ REQUIMTE/LAQV, Science Chemical Department, Faculty of Pharmacy of University of Porto, Rua Jorge Viterbo Ferreira, 228, 4050-313 Porto, Portugal

${ }^{c}$ Dpto. Nutrición y Bromatología II, Facultad de Farmacia, Universidad Complutense de Madrid (UCM), Pza Ramón y Cajal, s/n, E-28040 Madrid, Spain

${ }^{d}$ Laboratory of Separation and Reaction Engineering (LSRE), Associate Laboratory LSRE/LCM, Polytechnic Institute of Bragança, Campus de Santa Apolónia, 1134, 5301-857 Bragança, Portugal

${ }^{e}$ School of Health, Polytechnic Institute of Bragança, Av. D. Afonso V, 5300-121 Bragança, Portugal

${ }^{f}$ GIP-USAL, Faculty of Pharmacy, University of Salamanca, Campus Miguel de Unamuno, 37007 Salamanca, Spain

$\dagger$ Electronic supplementary information (ESI) available. See DOI: 10.1039/ c6fo01042c
}

pounds with antioxidant and antimicrobial properties important for clinical applications ${ }^{5,6}$ and food preservative purposes. ${ }^{7}$ Fragaria vesca L., commonly known as wild strawberry or woodland strawberry, is an important fruit consumed worldwide. It belongs to the Rosaceae family and grows spontaneously in mountain zones, and is also commonly found on roadsides and slopes. ${ }^{4,8}$ As a wild plant, its productivity is lower than commercial varieties, however it is well known for its strongly flavored berries that are traditionally used in the preparation of sauces, jams, juices, syrups, dairy products and even liqueurs and cosmetic products. ${ }^{9-11}$ Fragaria vesca fruits can be consumed either fresh or in infusion preparations that are used in folk medicine for the treatment of intestinal disorders, and they also show diuretic and antidiarrheal properties. $^{12,13}$ It has also been proven that its polysaccharide extract shows anticoagulant activity. ${ }^{12}$

The study of the nutritional properties of foodstuffs is extremely important, since the synergistic effects between compounds can add other types of properties in addition to the nutritional ones, and for this reason a balanced diet containing such elements can help in the maintenance of human health. ${ }^{14}$ The sugar composition in cultivated ${ }^{4}$ and wild ${ }^{15} F$. vesca fruits has been studied, as well as organic acids, ${ }^{4,9,16}$ mineral $^{9}$ and dietary fiber composition. ${ }^{17}$ Nevertheless, no complete studies on the nutritional and phytochemical characterization of wild $F$. vesca fruits have been found in the literature. In particular, to the authors' best knowledge, the composition of vitamins $\mathrm{B}_{9}$ and $\mathrm{C}$ has never been reported. On the other hand, the study of 
its bioactive properties such as antioxidant and antimicrobial activities could open new opportunities for application in food, pharmaceutical or cosmetic sectors.

The bioactive properties of strawberry plants have been linked to the presence of phenolic compounds, mainly hydroxycinnamic and ellagic acid derivatives (e.g., ellagitannins), flavonols, anthocyanins and proanthocyanidins. ${ }^{18-25}$ The antioxidant activity of $F$. vesca fruits has been studied, ${ }^{4,26}$ as well as the total phenolic content ${ }^{23,25-29}$ and phenolic composition, including anthocyanins. ${ }^{23,25,27,29}$ Nonetheless, studies on the antimicrobial capacity and biofilm production inhibition of F. vesca fruits could not be found.

In the present work, complete nutritional and phytochemical characterization of $F$. vesca fruits has been carried out. Furthermore, hydromethanolic extracts and infusions were prepared and evaluated for their antioxidant, antibacterial and biofilm formation inhibition activities, which were correlated with the composition in phenolic compounds.

\section{Materials and methods}

\subsection{Standards and reagents}

Acetonitrile, $n$-hexane and ethyl acetate were of HPLC grade from Fisher Scientific (Lisbon, Portugal). Formic acid was purchased from Prolabo (VWR International, France). Fatty acids methyl ester (FAME) reference standard mixture (standard 47885-U) was purchased from Sigma-Aldrich (St Louis, MO, USA), as well as trolox (6-hydroxy-2,5,7,8-tetramethylchroman2-carboxylic acid), L-ascorbic acid, tocopherols, sugar and organic acid standards, nitric acid, and hydrochloric acid, 5- $\mathrm{CH}_{3}-\mathrm{H}_{4}$ folate monoglutamate (ref. 16252; Schircks laboratories, Jona, Switzerland), pteroyl diglutamic acid (ref. 16235; Schircks laboratories, Jona, Switzerland), pancreatic chicken homogenate (Pel Freez, Rogers, Arkansas), rat serum, $\mathrm{NaBH}_{4}$, formaldehyde and octanol. Micro and macroelement standards (>99\% purity), as well as $\mathrm{LaCl}_{2}$ and $\mathrm{CsCl}(>99 \%$ purity) were purchased from Merck (Darmstadt, Germany). Phenolic standards were from Extrasynthèse (Genay, France). 2,2Diphenyl-1-picrylhydrazyl (DPPH) was obtained from Alfa Aesar (Ward Hill, MA, USA). All other general laboratory reagents were purchased from Panreac Química S.L.U. (Barcelona, Spain). Water was treated in a Milli-Q water purification system (TGI Pure Water Systems, Greenville, SC, USA).

\subsection{Samples and preparation of hydromethanolic extracts and infusions}

The samples of wild Fragaria vesca $\mathrm{L}$. fruits (harvested fully maturated) were collected in Serra da Nogueira (41 $43^{\prime} 12^{\prime \prime} \mathrm{N}, 6^{\circ} 51^{\prime}$ $\left.0^{\prime \prime} \mathrm{W}\right)$, Bragança, North-eastern Portugal, in July 2013. The fruits were conditioned in cooling boxes and transported to the laboratory. Voucher specimens (no. 9687) were deposited in the School of Agriculture Herbarium (BRESA) at the Polytechnic Institute of Bragança, Portugal. The samples were lyophilized (FreeZone 4.5, Labconco, Kansas, MO, USA), reduced to a fine dried powder (20 mesh) and mixed to obtain a homogenate sample.
For hydromethanolic extract preparations, each sample $(1 \mathrm{~g})$ was extracted by stirring with $30 \mathrm{~mL}$ of methanol/water $\left(80: 20 \mathrm{v} / \mathrm{v}\right.$, at $25^{\circ} \mathrm{C}$ at $\left.150 \mathrm{rpm}\right)$ for $1 \mathrm{~h}$, followed by filtration through Whatman filter paper no. 4. The residue was then extracted with an additional $30 \mathrm{~mL}$ portion of the hydromethanolic mixture and both extracts were combined. Afterwards, the extracts were evaporated under reduced pressure (rotary evaporator Büchi R-210, Flawil, Switzerland) and further lyophilized.

To prepare the infusions, each sample (500 mg) was added to $100 \mathrm{~mL}$ of boiled distilled water $\left(\mathrm{pH} \mathrm{6.6)}\right.$ at $100{ }^{\circ} \mathrm{C}$ and left to stand at room temperature for $5 \mathrm{~min}$. Then the samples were filtered under reduced pressure $(0.22 \mu \mathrm{m})$, frozen and lyophilized for further analysis.

For anthocyanin extract preparation, the powdered sample $(1 \mathrm{~g})$ was extracted with $30 \mathrm{~mL}$ of methanol containing $0.5 \%$ trifluoroacetic acid (TFA), and filtered through Whatman filter paper no. 4. The residue was then re-extracted with an additional $30 \mathrm{~mL}$ portion of $0.5 \%$ TFA in methanol. The combined extracts were evaporated at $35^{\circ} \mathrm{C}$ to remove the methanol, and re-dissolved in water. For purification, the extract solution was deposited into a C-18 SepPak® Vac 3cc cartridge (Phenomenex), previously activated with methanol followed by water; sugars and more polar substances were removed by passing through $10 \mathrm{~mL}$ of water and anthocyanins were further eluted with $5 \mathrm{~mL}$ of methanol : water $(80: 20$, v/v) containing $0.1 \%$ TFA. The extract was concentrated under vacuum, lyophilized, re-dissolved in $1 \mathrm{~mL}$ of $20 \%$ aqueous methanol and filtered through a $0.22 \mu \mathrm{m}$ disposable LC filter disk for HPLC analysis.

\subsection{Nutritional value of the fruits}

2.3.1. Proximate composition. The sample was analyzed for the crude protein content (AOAC, 991.02), crude fat (AOAC, 989.05), carbohydrates and ash (AOAC, 935.42) according to the AOAC procedures. ${ }^{30}$ Dietary fiber composition (AOAC, 993.19 and 991.42) were analyzed according to the method described by Latimer et $a .^{31}$ Total energy was calculated according to the following equation: ${ }^{32}$

$$
\begin{aligned}
\text { Energy }(\text { kcal per } 100 \mathrm{~g})= & 4 \times(\mathrm{g} \text { proteins }+\mathrm{g} \text { carbohydrates }) \\
& +2 \times(\mathrm{g} \text { total dietary fiber })+9 \times(\mathrm{g} \text { fat }) .
\end{aligned}
$$

2.3.2. Fatty acids. Fatty acids were determined by GC-FID (DANI model GC 1000 instrument, Contone, Switzerland) as previously described in ref. 33 and 34 and the results were expressed as relative percentage of each fatty acid.

\subsection{Chemical characterization of the fruits and infusions}

2.4.1. Soluble sugars. Free sugars were determined by HPLC coupled to an RI detector (Knauer, Smartline system 1000, Berlin, Germany) using the internal standard (IS, melezitose) method or the external standard method for infusions, as previously described in ref. 33 and 34 . The results were expressed in $\mathrm{g}$ per $100 \mathrm{~g}$ of fresh weight of the fruits or in $\mathrm{mg}$ per $100 \mathrm{~mL}$ of infusion. 
2.4.2 Organic acids. Organic acids were determined following a procedure previously described in ref. 35 and 34 and the analysis was performed by ultra-fast liquid chromatography coupled to a photodiode array detector (UFLC-PDA; Shimadzu Corporation, Kyoto, Japan), using $215 \mathrm{~nm}$ and $245 \mathrm{~nm}$ (for ascorbic acid) as preferred wavelengths. The results were expressed in $\mathrm{g}$ per $100 \mathrm{~g}$ of fresh weight of the fruits or in $\mathrm{mg}$ per $100 \mathrm{~mL}$ of infusion.

2.4.3. Minerals. Mineral element (930.05 of AOAC) analysis was performed according to a methodology previously described. ${ }^{34,36,37}$ All measurements were performed in atomic absorption spectroscopy (AAS) with air/acetylene flame in Analyst 200 Perkin Elmer equipment (Perkin Elmer, Waltham, MA, USA), comparing absorbance responses with $>99.9 \%$ purity analytical standard solutions for AAS made with $\mathrm{Fe}\left(\mathrm{NO}_{3}\right)_{3}, \mathrm{Cu}\left(\mathrm{NO}_{3}\right)_{2}, \mathrm{Mn}\left(\mathrm{NO}_{3}\right)_{2}, \mathrm{Zn}\left(\mathrm{NO}_{3}\right)_{2}, \mathrm{NaCl}, \mathrm{KCl}, \mathrm{CaCO}_{3}$ and $\mathrm{Mg}$ band.

2.4.4. Folates (vitamin $\mathbf{B}_{\mathbf{9}}$ ). The folate content was determined according to the methodology previously described in ref. 34, 38 and separation was performed using an HPLC (Ecom, Prague, Czech Republic), joined to an automatic injector (AS-1555, Jasco, Easton, MD, USA), and to a fluorescence detector (FP-2020, Jasco, Easton, MD, USA). The results were expressed in $\mu \mathrm{g}$ per $100 \mathrm{~g}$ of fresh weight of the fruits or in $\mu \mathrm{g}$ per $100 \mathrm{~mL}$ of infusion.

2.4.5. Tocopherols (vitamin E). Tocopherols were determined following a procedure previously described in ref. 33 and 34, using a HPLC system (Knauer, Smartline system 1000, Berlin, Germany) coupled to a fluorescence detector (FP-2020; Jasco, Easton, USA) programmed for excitation at $290 \mathrm{~nm}$ and emission at $330 \mathrm{~nm}$, using the IS (tocol) method for quantification. The results were expressed in $\mu \mathrm{g}$ per $100 \mathrm{~g}$ of fresh weight of the fruits or in $\mu \mathrm{g}$ per $100 \mathrm{~mL}$ of infusion.

\subsection{Individual phenolic profile and bioactive properties of fruits hydromethanolic extracts and infusions}

2.5.1. Phenolic compounds analysis. The phenolic profile was determined in the lyophilized extracts and infusions redissolved in methanol:water $(80: 20, \mathrm{v} / \mathrm{v})$ and pure water, respectively, by HPLC-DAD-MS/ESI (Hewlett-Packard 1100, Agilent Technologies, Santa Clara, CA, USA), as previously described..$^{39-41}$ Double online detection was carried out with a diode array detector (DAD, 280 and $370 \mathrm{~nm}$ as the preferred wavelengths) connected in line with a mass spectrometer (API 3200 Qtrap, Applied Biosystems, Darmstadt, Germany). The identification of the different phenolic compounds was performed by comparison with available commercial standards, or tentatively identified using the reported data from the literature. For quantitative analysis, a calibration curve for each available phenolic standard was created, when no commercial standard was available a similar compound from the same phenolic group was used as a standard. The results were expressed in $\mathrm{mg}$ per $\mathrm{g}$ of lyophilized extract or infusion.

2.5.2. Anthocyanins analysis. Anthocyanins were determined in the lyophilized extracts and infusions (re-dissolved in methanol: water $(80: 20, \mathrm{v} / \mathrm{v})$ and pure water, respectively) by HPLC (Hewlett-Packard 1100) as previously described. ${ }^{39}$ Double online detection was carried out in a DAD, using $520 \mathrm{~nm}$ as the preferred wavelength, and in an MS connected to the HPLC system via the DAD cell outlet. The identification of the different anthocyanins was performed by comparison with the available commercial standards, or tentatively identified using the reported data from the literature. For quantitative analysis, a calibration curve for each available anthocyanin standard was constructed; when no commercial standard was available a similar compound was used as a standard. The results were expressed in $\mu \mathrm{g}$ per $\mathrm{g}$ of lyophilized extract or infusion.

2.5.3. Antioxidant activity evaluation. The lyophilized extracts and infusions were re-dissolved in methanol:water $(80: 20, \mathrm{v} / \mathrm{v})$ and water, respectively, to obtain stock solutions of $2.5 \mathrm{mg} \mathrm{mL}^{-1}$, which were further diluted to obtain a range of concentrations for antioxidant activity evaluation by DPPH radical-scavenging activity, reducing power, inhibition of $\beta$-carotene bleaching and lipid peroxidation inhibition in porcine brain homogenates (TBARS). ${ }^{33,40,41}$ The final results

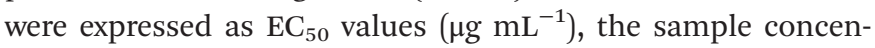
tration providing $50 \%$ of antioxidant activity or 0.5 of absorbance in the reducing power assay. Trolox was used as a positive control.

2.5.4. Antibacterial activity evaluation. The microorganisms used were clinical isolates from patients hospitalized in various departments of the Local Health Unit of Bragança and Hospital Center of Trás-os-Montes and Alto-Douro Vila Real, Northeast of Portugal (ESI $\dagger$ ).

MIC determinations were performed by the microdilution method and the rapid $p$-iodonitrotetrazolium chloride (INT) colorimetric assay following the methodology described by the authors. ${ }^{42}$ MIC was defined as the lowest extract concentration that prevented this change and exhibited inhibition of bacterial growth.

The biofilm assay was carried out adapting the protocol described by the authors. ${ }^{42}$ The results for this test were given as the percentage of biofilm formation inhibition by applying the following formula:

$$
\begin{aligned}
& \text { Biofilm formation inhibition percentage } \\
& \quad=100-\left(\mathrm{OD}_{\text {assay }} / \mathrm{OD}_{\text {control }}\right) \times 100
\end{aligned}
$$

\subsection{Statistical analysis}

Three different samples were used and all the extractions and assays were performed in triplicate. The results were expressed as mean values and standard deviation (SD), being analysed using a Student's $t$-test, with $\alpha=0.05$ (SPSS v. 22.0 program, IBM Corp., Armonk, NY, USA).

\section{Results and discussion}

\subsection{Nutritional composition of $F$. vesca fruits}

The results regarding the proximate composition, dietary fiber and fatty acid content of wild F. vesca fruits are pre- 
Table 1 Nutritional value, dietary fiber and fatty acids content in fruits of wild Fragaria vesca L. (mean \pm SD)

Nutritional value ( $g$ per $\mathbf{1 0 0} \mathbf{g} \mathbf{f w}$ )
Moisture
Fat
Proteins
Ash
Total available carbohydrates
Total dietary fiber
Energy (kcal per $100 \mathrm{~g}$ fw)
Dietary fiber ( $\mathbf{g}$ per $\mathbf{1 0 0} \mathrm{g}$ fw)
Soluble dietary fiber
Insoluble dietary fiber
Fatty acids (relative percentage)
C10:0
C12:0
C14:0
C15:0
C16:0
C18:1n9
C18:2n6
C18:3n6
C18:3n3
C20:1
C20:2
C20:3n6
C22:1n9
SFA
MUFA
PUFA

$81.72 \pm 0.01$

$0.61 \pm 0.01$

$0.51 \pm 0.01$

$1.00 \pm 0.01$

$10.42 \pm 0.23$

$5.78 \pm 0.21$

$56.13 \pm 0.69$

$5.25 \pm 0.17$

$0.62 \pm 0.07$

$0.02 \pm 0.002$

$0.03 \pm 0.002$

$0.05 \pm 0.004$

$0.02 \pm 0.003$

$2.76 \pm 0.06$

$1.24 \pm 0.013$

$10.59 \pm 0.07$

$40.06 \pm 0.24$

$43.37 \pm 0.14$

$1.00 \pm 0.06$

$0.24 \pm 0.01$

$0.23 \pm 0.03$

$0.39 \pm 0.03$

$2.88 \pm 0.07$

$2.63 \pm 0.10$

$94.49 \pm 0.04$
The results are expressed on fresh weight basis. C10:0 - capric acid, C12:0 - lauric acid, C14:0 - myristic acid, C15:0 - pentadecanoic acid, C16:0 - palmitic acid, C18:1n9 - oleic acid, C18:2n6 - linoleic acid, C18:3n3 - linolenic acid, C18:3n6 - $\gamma$-linolenic acid methyl ester, C20:0 - arachidic acid, C20:1 - cis-11-eicosenoic acid, C20:2 - cis-11,14eicosadienoic acid, C20:3n6 - cis-8,11,14-eicosatrienoic acid, C22:1n9 erucic acid; SFA - saturated fatty acids, MUFA - monounsaturated fatty acids, PUFA - polyunsaturated fatty acids.

sented in Table 1. Carbohydrates and dietary fiber were the major macronutrients, followed by fat, ash and proteins. In terms of the dietary fiber content, soluble dietary fiber (mainly pectins) was the predominant one, with a content higher than the one described by Ramulu and $\mathrm{Rao}^{17}$ in F. vesca fruits from India $(0.7 \mathrm{~g}$ per $100 \mathrm{~g}$ fw). It is described that the daily consumption of fiber has beneficial health effects, mainly in the digestive tract or even in the prevention of diabetes; especially soluble dietary fiber has a very large impact on the level of fat and arteriosclerosis in humans. The current recommended consumption of total dietary fiber is estimated to be $20 \mathrm{~g}$ per person per day, so that the consumption of just $100 \mathrm{~g}$ of fresh wild strawberry would cover almost one-third of the recommended intake. ${ }^{43}$ Regarding the fatty acids profile, 13 different compounds were identified, notably a predominance of polyunsaturated fatty acids, mainly due to the presence of linolenic (C18:3n3), $\gamma$-linolenic (C18:3n6) and linolenic (C18:2n6) acids.

\subsection{Chemical composition of $\boldsymbol{F}$. vesca fruits and infusions}

The results of the composition of $F$. vesca fruits and infusions in soluble sugars, organic acids, mineral elements, folates and tocopherols are given in Table 2. The profile was very similar, expect for tocopherols. Sucrose was the major soluble sugar found in the fruits and in the infusions, followed by fructose and glucose. Very similar contents were reported by Doumett et $a l^{4}$ in various cultivars of $F$. vesca fruits from Italy and by Ornelas-Paz et al. ${ }^{16}$ in Fragaria $\times$ ananassa Duch., Cv. Albion from Mexico; however, lower contents were described by Blanch et al. ${ }^{15}$ in Fragaria vesca cv. Mara de Bois fruits from Spain (sucrose $=1.49 \mathrm{~g}$ per $100 \mathrm{~g} \mathrm{fw}$ ).

Table 2 Soluble sugars, organic acids, minerals, folates and tocopherols content in wild Fragaria vesca L. fruits and infusions (mean \pm SD)

\begin{tabular}{lcr}
\hline Soluble sugars & $\begin{array}{l}\text { Fruits } \\
\text { g per } 100 \mathrm{~g} \mathrm{fw}\end{array}$ & \multicolumn{1}{l}{$\begin{array}{l}\text { Infusions } \\
\text { mg per } 100 \mathrm{~mL}\end{array}$} \\
\hline Fructose & $1.60 \pm 0.01$ & $33.43 \pm 0.80$ \\
Glucose & $1.44 \pm 0.01$ & $30.07 \pm 0.42$ \\
Sucrose & $3.20 \pm 0.02$ & $66.44 \pm 1.50$ \\
Raffinose & $0.070 \pm 0.001$ & $1.32 \pm 0.02$ \\
Sum & $6.31 \pm 0.03$ & $131.26 \pm 2.75$ \\
\hline
\end{tabular}

\begin{tabular}{lcl}
\hline Organic acids & g per $100 \mathrm{~g}$ fw & $\mathrm{mg}$ per $100 \mathrm{~mL}$ \\
\hline Oxalic acid & $0.040 \pm 0.001$ & $\operatorname{tr}$ \\
Malic acid & $0.74 \pm 0.01$ & $1.024 \pm 0.001$ \\
Ascorbic & $0.040 \pm 0.001$ & $\operatorname{tr}$ \\
Citric acid & $5.59 \pm 0.04$ & $25.98 \pm 0.002$ \\
Succinic acid & $1.14 \pm 0.04$ & $5.72 \pm 0.01$ \\
Sum & $7.55 \pm 0.01$ & $32.7 \pm 0.3$ \\
\hline
\end{tabular}

\begin{tabular}{lll}
\hline Microelements & mg per $100 \mathrm{~g} \mathrm{fw}$ & mg per $100 \mathrm{~mL}$ \\
\hline $\mathrm{Fe}$ & $0.72 \pm 0.01$ & $0.059 \pm 0.001$ \\
$\mathrm{Mn}$ & $1.27 \pm 0.09$ & $0.106 \pm 0.002$ \\
$\mathrm{Zn}$ & $0.19 \pm 0.01$ & $0.034 \pm 0.001$
\end{tabular}

\begin{tabular}{lcc}
\hline Macroelements & mg per $100 \mathrm{~g} \mathrm{fw}$ & mg per $100 \mathrm{~mL}$ \\
\hline $\mathrm{Ca}$ & $11.8 \pm 0.3$ & $4.4 \pm 0.2$ \\
$\mathrm{Mg}$ & $2.9 \pm 0.2$ & $3.64 \pm 0.23$ \\
$\mathrm{~K}$ & $18.7 \pm 0.5$ & $2 \pm 0.1$ \\
\hline
\end{tabular}

\begin{tabular}{lll}
\hline Folate $\left(\right.$ vitamin $\left.\mathrm{B}_{9}\right)$ & $\mu \mathrm{g}$ per $100 \mathrm{~g}$ fw & $\mu \mathrm{g}$ per $100 \mathrm{~mL}$ \\
\hline $29.33 \pm 0.35$ & $4.044 \pm 0.001$ \\
\hline
\end{tabular}

\begin{tabular}{lcl}
\hline Tocopherols & mg per $100 \mathrm{~g}$ fw & $\mu \mathrm{g}$ per $100 \mathrm{~mL}$ \\
\hline$\alpha$-Tocopherol & $0.50 \pm 0.01$ & $0.30 \pm 0.02$ \\
$\beta$-Tocopherol & $0.050 \pm 0.001$ & nd \\
$\gamma$-Tocopherol & $1.52 \pm 0.01$ & nd \\
$\delta$-Tocopherol & $0.29 \pm 0.01$ & nd \\
Sum & $2.35 \pm 0.01$ & $0.30 \pm 0.02$
\end{tabular}

The results in fruits are expressed on fresh weight basis; nd - not detected; $\operatorname{tr}-$ traces $\left(<\mathrm{LOQ}: 42 \mu \mathrm{g} \mathrm{mL} \mathrm{mL}^{-1}\right.$ quinic acid and $50 \mu \mathrm{g} \mathrm{mL} \mathrm{m}^{-1}$ for ascorbic acid); $\mathrm{Fe}$ - iron, $\mathrm{Cu}$ - cooper, $\mathrm{Mn}$ - manganese, $\mathrm{Zn}$ - zinc, $\mathrm{Ca}$ - calcium, $\mathrm{Mg}$ - magnesium, $\mathrm{K}$ - potassium. Calibration curves for organic acids: oxalic acid $\left(y=9 \times 106 x+377946, R^{2}=0.994\right)$; malic acid $\left(y=863548 x+55571, R^{2}=0.999\right)$; ascorbic acid $(y=108 x+$ $\left.751815, R^{2}=0.998\right)$; citric acid $\left(y=106 x+16276, R^{2}=1\right)$; succinic acid $\left(y=603298 x+4994.1, R^{2}=1\right)$. 
Citric and succinic acids were the most abundant organic acids in the fruits and infusions; ${ }^{4}$ citric acid was also described as the major organic acid in $F$. vesca fruits but in lower levels ( $1.29 \mathrm{~g}$ per $100 \mathrm{~g} \mathrm{fw}$ ), followed by malic acid, while no more organic acids were detected. The same was observed in F. vesca fruits from Italy. ${ }^{9}$ Ornelas-Paz et al. ${ }^{16}$ described citric acid as the major one, followed by malic acid, and also with the presence of ascorbic acid in cultivars of Fragaria $x$ ananassa.

Related to mineral composition, the microelements found in higher amounts in both samples were manganese (Mn), followed by iron (Fe) and zinc ( $\mathrm{Zn})$. Copper $(\mathrm{Cu})$ was not detected in the studied samples, however Caruso et al. ${ }^{9}$ described the presence of copper in the hydroponic cultures of $F$. vesca fruits. Regarding macroelements, potassium (K) was the major one in the fruits, while calcium $(\mathrm{Ca})$ was the most prevalent macroelement in the infusions. Magnesium (Mg) was also present in both samples. The mineral elements' concentration in infusions depends mainly on three factors: the linkages to the plant cell tissues, mainly in the insoluble dietary fiber fraction, the solvent employed for extraction and the temperature used to prepare the infusions that could help breaking down the connection between minerals and cell constituents, and influence the extraction yield of these elements. ${ }^{44}$ Folates (vitamin $\mathrm{B}_{9}$ ) were also detected both in fruits and in the corresponding infusions, ${ }^{34}$ folates were also detected in the infusions of wild roots and vegetative parts of wild $F$. vesca, but in higher amounts. The folate content was also determined in other fruits, such as coconuts and pineapples, but it was found in significantly lower amounts $(10.0$ and $10.5 \mu \mathrm{g}$ per $100 \mathrm{~g} \mathrm{fw}$, respectively). ${ }^{45}$ The recommended daily intake for folates is $200 \mu \mathrm{g}$ day $^{-1}$, according to the EC Regulation number, ${ }^{29}$ which leads to the conclusion that the daily consumption of $100 \mathrm{~g}$ of fresh fruit or $100 \mathrm{~mL}$ of its infusion would cover $15 \%$ and $2 \%$ of the recommended intake, respectively. In terms of tocopherols which are mainly found in the seeds, the four forms were quantified in the fruits, $\gamma$-tocopherol being the main one, followed by $\alpha$-tocopherol. In the infusions, only $\alpha$-tocopherol was found, but not $\gamma$-tocopherol, which may be due to the different stability of the compounds under heat treatment. Britz et al. ${ }^{46}$ observed that $\alpha$-tocopherol had a tendency to increase at high temperatures after thermal treatment in brown rice, whereas the opposite was observed for $\gamma$-tocopherol.

\subsection{Individual phenolic profile in $F$. vesca hydromethanolic extracts and infusions}

Table 3 presents the peak characteristics (retention time, $\lambda_{\max }$ in the visible region, mass spectral data), tentative identifications and quantification of phenolic compounds in hydromethanolic extracts and infusions prepared from wild $F$. vesca fruits. An exemplificative phenolic profile of the hydromethanolic extracts is shown in Fig. 1A and B. Thirty-two phenolic compounds were identified, one phenolic acid, twenty-two ellagic acid/HHDP derivatives, two flavan-3-ols, one dihydroflavonol and six anthocyanins.
Peak 10 was the only phenolic acid derivative found in F. vesca fruits, being tentatively identified as ferulic acid dihexoside, presenting a pseudomolecular ion $[\mathrm{M}-\mathrm{H}]^{-}$at $\mathrm{m} / \mathrm{z}$ 517 releasing an $\mathrm{MS}^{2}$ fragment at $\mathrm{m} / \mathrm{z}$ 193, attributed to a ferulic acid and corresponding to the loss of two hexose moieties $[\mathrm{M}-\mathrm{H}-162-162]^{-}$. Peaks 6 and 8 were the only detected flavan-3-ol, being tentatively identified as procyanidin dimer B1 and (+)-catechin, respectively, which were previously reported in F. vesca fruits ${ }^{23}$ and in $F$. vesca roots and vegetative parts ${ }^{40,41}$ Peak 22 was identified as the dihydroflavonol taxifolin-3-O-arabinoside based on its molecular ion and fragmentation pattern, as previously described in the roots of wild F. vesca. ${ }^{40}$

As for $F$. vesca roots $^{40}$ and vegetative parts, ${ }^{41}$ ellagic acid derivatives represent the largest group of phenolic compounds identified in $F$. vesca fruits, although these latter revealed lower concentrations. This can be explained by the fact that such compounds have a preferred tendency to accumulate in certain types of tissues, such as leaves and roots, rather than in fruit tissues, ${ }^{18}$ as well as to the greater moisture content existing in the fruits. Ellagic acid rhamnosides (peaks 19 and 21), ellagic acid (peak 23) and dimethyl ellagic acid pentosides (peaks 25 and 26) were previously reported in roots and vegetative parts of $F$. vesca. ${ }^{40,41}$ Peaks $13\left([\mathrm{M}-\mathrm{H}]^{-}\right.$at $m / z$ 463) and 18 $\left([\mathrm{M}-\mathrm{H}]^{-}\right.$at $\left.m / z 433\right)$ showed UV spectra similar to ellagic acid and an $\mathrm{MS}^{2}$ fragment at $\mathrm{m} / \mathrm{z} 301$ (ellagic acid) from the losses of $162 \mathrm{mu}$ and $132 \mathrm{mu}$, respectively, being tentatively identified as ellagic acid hexoside and ellagic acid pentoside, respectively. Similarly, peaks $20\left([\mathrm{M}-\mathrm{H}]^{-}\right.$at $\left.m / z 477\right)$ and 24 $\left([\mathrm{M}-\mathrm{H}]^{-}\right.$at $\left.m / z 447\right)$ were tentatively identified as methyl ellagic acid hexoside and pentoside, respectively. Both peaks presented a $\mathrm{MS}^{2}$ fragment at $\mathrm{m} / \mathrm{z} 315$, corresponding to the loss of an hexosyl ([M $\left.-\mathrm{H}-477-301]^{-} ; 162 \mathrm{mu}\right)$ and pentosyl moiety ([M - H $-447-301]^{-}$; $\left.132 \mathrm{mu}\right)$, respectively, and also a second fragment ion at $\mathrm{m} / \mathrm{z} 301$ (ellagic acid), pointing to the further loss of a methyl group.

The remaining compounds correspond to hydrolysable tannins, namely bis-HHDP-glucose isomers (peaks 1 and 2), galloyl-HHDP-glucose (peak 7), galloyl-bis-HHDP-glucose isomers (peaks 12, 14 and 16), castalagin/vescalagin (peak 15) and Sanguiin h10 (peak 17). All these compounds were previously reported in $F$. vesca roots and vegetative parts, ${ }^{40,41}$ as well as by other authors in fruits of $F$. vesca $^{23-25}$ and F. chiloensis spp. ${ }^{21}$ Sanguiin h10 (peak 17) was the main compound found in the hydromethanolic extracts and infusions of the fruits, as also reported in ref. 34 and 40. Peaks 3 and 5 $\left([\mathrm{M}-\mathrm{H}]^{-}\right.$at $m / z$ 951) released $\mathrm{MS}^{2}$ fragments at 907,783 and 301 , corresponding to the loss of a carboxylic group (44 mu), a gallic acid unit (168 mu) and the tris-galloyl-hexoside residue $(488+162 \mathrm{mu})$, respectively, therefore being tentatively identified as two tris-galloyl-HHDP hexose isomers, already reported in fruits of $F$. vesca in ref. 23. Peak $11\left([\mathrm{M}-\mathrm{H}]^{-}\right.$ion at $\left.\mathrm{m} / \mathrm{z} 785\right)$ presented $\mathrm{MS}^{2}$ fragment ions at $\mathrm{m} / \mathrm{z} 615$ (loss of gallic acid, $170 \mathrm{mu}$ ), $\mathrm{m} / \mathrm{z} 463$ (further loss of a galloyl moiety, $152 \mathrm{mu}$ ) and $\mathrm{m} / \mathrm{z} 301$ (loss of an hexose residue, $162 \mathrm{mu}$ ), being tentatively identified as digalloyl-HHDP-hexose. This compound was pre- 
Table 3 Retention time $\left(R_{\mathrm{t}}\right)$, wavelengths of maximum absorption in the visible region $\left(\lambda_{\max }\right)$, mass spectral data, tentative identification, phenolic

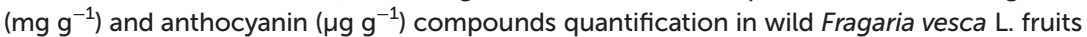

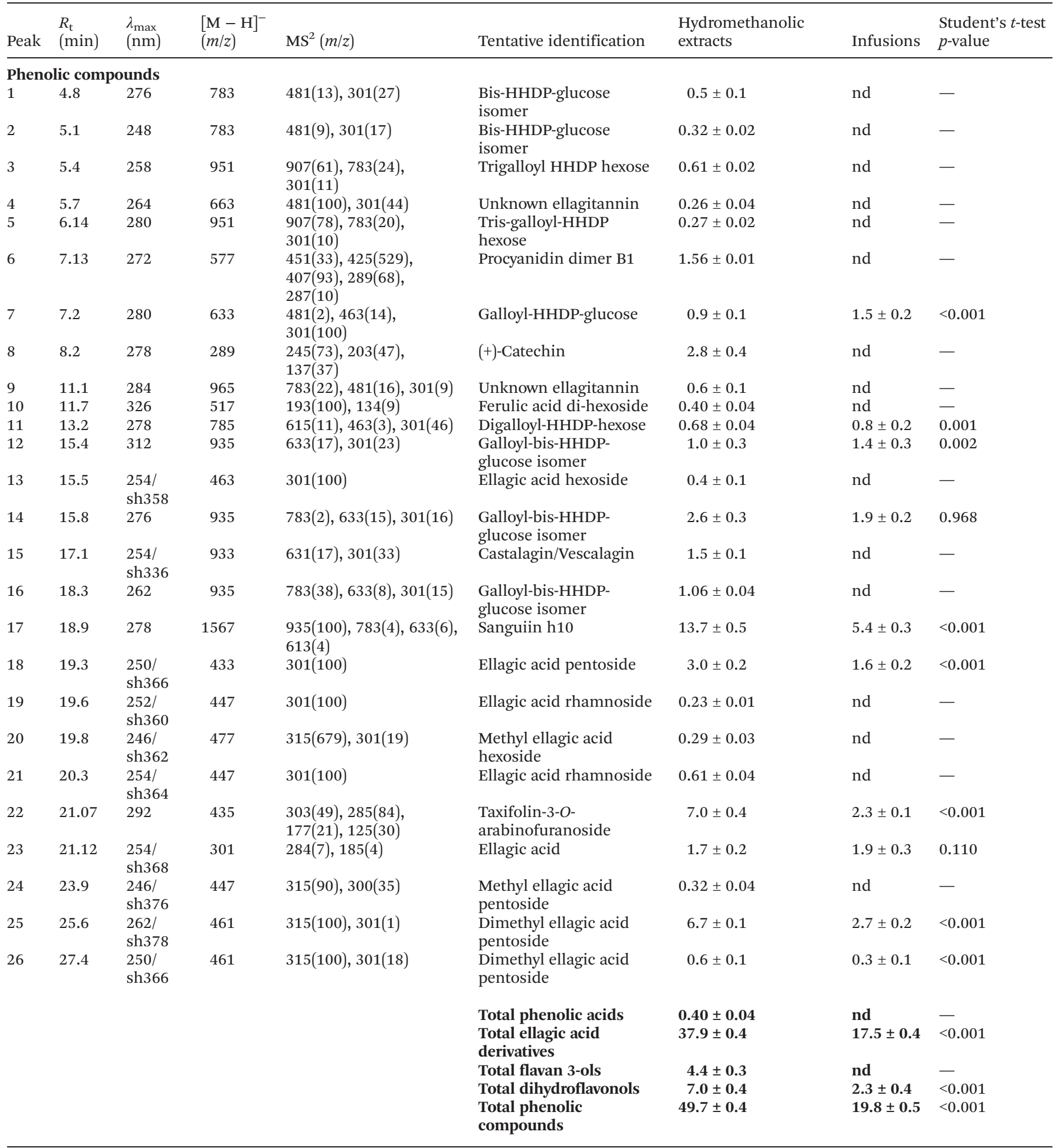

Anthocyanin compounds

\begin{tabular}{|c|c|c|c|c|c|c|c|c|}
\hline Peak & $\begin{array}{l}R_{\mathrm{t}} \\
(\min )\end{array}$ & $\begin{array}{l}\lambda_{\max } \\
(\mathrm{nm})\end{array}$ & $\begin{array}{l}{[\mathrm{M}+\mathrm{H}]^{+}} \\
(\mathrm{m} / \mathrm{z})\end{array}$ & $\operatorname{MS}^{2}(m / z)$ & Tentative identification & $\begin{array}{l}\text { Hydromethanolic } \\
\text { extracts }\end{array}$ & Infusions & $\begin{array}{l}\text { Student's } t \text {-test } \\
p \text {-value }\end{array}$ \\
\hline 27 & 16.6 & 514 & 449 & $287(100)$ & Cyanidin-3-glucoside & $2.6 \pm 0.1$ & $0.304 \pm 0.002$ & $<0.001$ \\
\hline 28 & 19.34 & 504 & 433 & $271(100)$ & Pelargonidin-3-glucoside & $4.6 \pm 0.2$ & $0.477 \pm 0.004$ & $<0.001$ \\
\hline
\end{tabular}


Table 3 (Contd.)

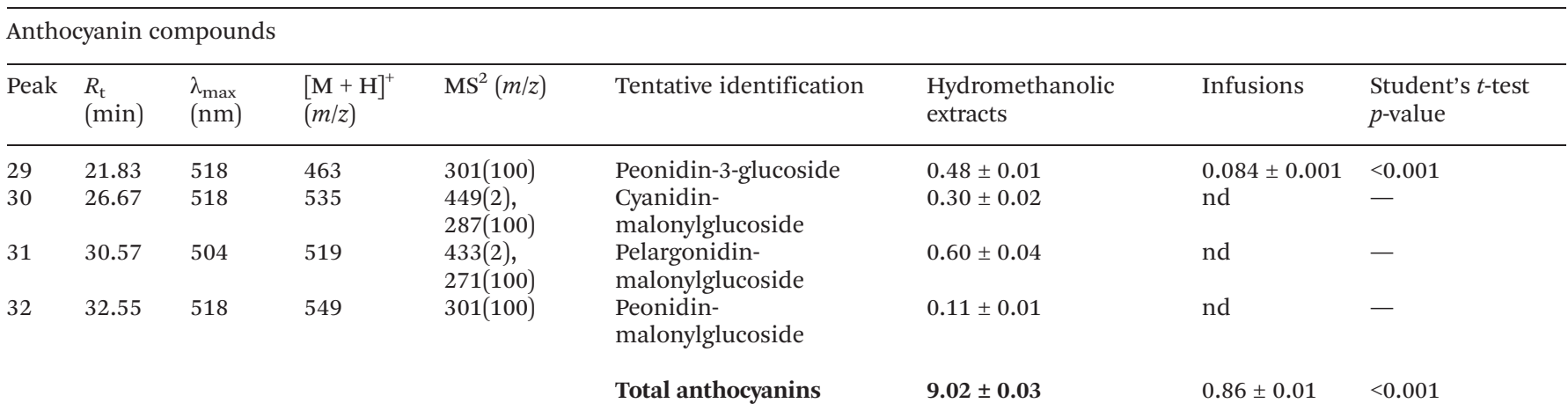

Standard calibration curves: catechin $\left(y=158.42 x+11.38, R^{2}=0.999\right)$; cyanidin-3-O-glucoside $\left(y=630276 x+153.83, R^{2}=0.999\right)$; ellagic acid $(y=$ $\left.36.466 x+35.44, R^{2}=0.999\right)$; ferulic acid $\left(y=525.36 x+233.82, R^{2}=0.999\right)$; pelargonidin-3-O-glucoside $\left(y=268748 x+71.423, R^{2}=0.999\right)$; peonidin-3-O-glucoside $\left(y=537017 x+71.469, R^{2}=0.999\right)$; taxifolin $\left(y=224.31 x+148.41, R^{2}=0.999\right)$.

viously reported in fruits of $F$. vesca. ${ }^{23,24}$ Finally, peaks $4([\mathrm{M}-$ $\mathrm{H}]^{-}$at $\left.\mathrm{m} / \mathrm{z} 663\right)$ and $9\left([\mathrm{M}-\mathrm{H}]^{-}\right.$at $\mathrm{m} / z$ 965) could not be identified, although they corresponded to ellagitannins, as revealed by their UV spectra and the $\mathrm{MS}^{2}$ fragment ions observed at $m / z 481$ (HHDP-hexose unit) and 301 (ellagic acid). An unknown ellagitannin with the same characteristics as peak 9 was previously found in ref. 47 in the leaves of $F$. vesca. Peaks 27-32 corresponded to anthocyanins found in $F$. vesca fruits. Cyanidin-3-O-glucoside (peak 27), pelargonidin-3-O-glucoside (peak 28) and peonidin-3-O-glucoside (peak 29) were identified according to their retention, mass and UV-vis characteristics and comparison with commercial standards. Peaks 30-32 showed molecular weights 86 Da greater than the previous compounds, which allowed their tentative identification as the corresponding malonyl derivatives. All these anthocyanins have already been reported to be present in F. vesca berries in ref. 23. Pelargonidin-3-O-glucoside was the major anthocyanin found in both extracts, whereas the malonyl derivatives were only detected in the hydromethanolic extracts, maybe due to their lower polarity compared to the parent glucosides and/or a less efficient extraction in the case of infusions.

\subsection{Antioxidant and antibacterial activity of $\boldsymbol{F}$. vesca hydromethanolic extracts and infusions}

Data regarding the antioxidant and antibacterial activity of the hydromethanolic extracts and infusions obtained from wild F. vesca fruits are presented in Table 4. It is clearly evident that the antioxidant capacity of the hydromethanolic extracts is higher in comparison with the infusions, as observed in all the performed assays.

By analysing Table 4 it was verified that both hydromethanolic extracts and the infusions showed antibacterial activity against all Gram positive and Gram negative bacteria tested, including those with high antibiotic susceptibility and with extended spectrum beta-lactamase (Escherichia coli ESBL 1 and 2 and Klebsiella pneumoniae ESBL). The significant MIC values observed for bacteria associated with health care such as MRSA, Pseudomonas aeruginosa and Acinetobacter baumannii should also be noted. The hydromethanolic extracts also showed higher antibacterial activity than the infusions, presenting lower MIC values for the Gram negative bacteria Escherichia coli and Pseudomonas aeruginosa.

The biofilm assay was only performed for the hydromethanolic extracts, owing to their higher phenolic contents and antioxidant and antibacterial activities compared with the infusions. The extracts showed capacity to inhibit the formation of the biofilm in E. coli ESBL 1, E. coli ESBL 2, Klebsiella pneumoniae ESBL and MRSA, presenting percentages of inhibition for each bacteria of $47 \%, 49 \%, 62 \%$ and $85 \%$, respectively.

Correlation of total phenolic acids (TPA), total ellagic acid derivatives (TED), total flavan-3-ols (TF3O), total dihydroflavonols (TDF), total phenolic compounds (TPC) and total anthocyanins (TA) with the $\mathrm{EC}_{50}$ values obtained in the four antioxidant activity assays and the MIC values obtained in the antibacterial activity assay were performed (Table 4). The results showed high correlations with all the phenolic compound families found in both hydromethanolic extracts and infusions of $F$. vesca fruits. The best results were obtained for reducing power and TBARS inhibition with TPA $\left(r^{2}=0.9929\right.$ and 0.9916, respectively), TED ( $r^{2}=0.9967$ and 0.9954 , respectively), TF3O $\left(r^{2}=0.995\right.$ and 0.9937 , respectively), TPC $\left(r^{2}=0.9972\right.$ and 0.9958 , respectively) and TA $\left(r^{2}=0.998\right.$ and 0.9966 , respectively). For the antibacterial activity assay the same families of phenolic compounds showed the best results for $E$. coli and $P$. aeruginosa with TPA $\left(r^{2}=0.9938\right)$, TED $\left(r^{2}=0.9976\right)$, TF3O $\left(r^{2}=0.9959\right)$, TPC $\left(r^{2}=0.9959\right)$ and TA $\left(r^{2}=0.9989\right)$. These results are in accordance with other authors who proved the correlation between the presence of phenolic compounds and antimicrobial activity in natural extracts. ${ }^{48}$

In conclusion, the fruits of wild $F$. vesca represent a good source of carbohydrate soluble dietary fiber and polyunsaturated fatty acids, mainly linoleic and linolenic acids. They 

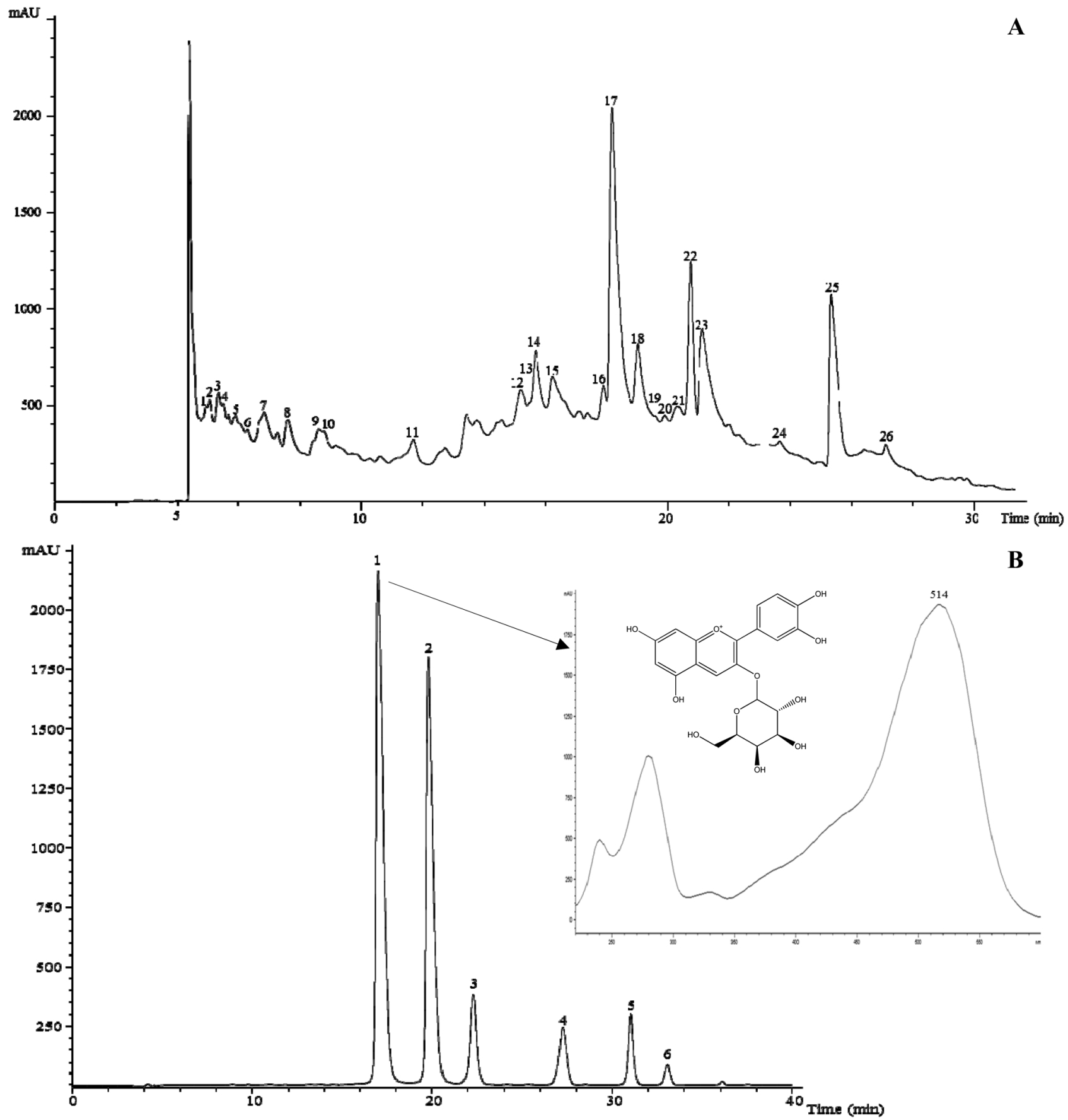

Fig. 1 HPLC phenolic profile obtained at $280 \mathrm{~nm}(\mathrm{~A})$ and $520 \mathrm{~nm}(\mathrm{~B})$ of the hydromethanolic extract prepared from wild Fragaria vesca L. fruits.

also showed to be a good source of sucrose, citric and succinic acid, vitamin $\mathrm{B}_{9}$ and vitamin $\mathrm{E}$ (mainly $\gamma$-tocopherol). Their infusions presented significant amounts of soluble sugars (sucrose and glucose) and citric acid, as well as some levels of folates and vitamin $\mathrm{E}$ (only $\alpha$-tocopherol) and trace amounts of ascorbic acid. Regarding phenolic composition, the hydromethanolic extracts showed much higher amounts than the infusions, ellagic acid derivatives (especially Sanguiin h10) and dihydroflavonols (taxifolin-3-O-arabinofuranoside) being the majority individual compounds. The hydromethanolic extracts also revealed higher antioxidant and antibacterial activity than the infusions, and also proved to have the capacity to inhibit biofilm formation. These bioactivities were highly correlated with the presence of phenolic compounds. Despite the lower contents of bioactive compounds in infusions of wild $F$. vesca compared to its fruits, the results obtained are of great novelty since both forms could be potentially applied in novel food products such as functional foods 
Table 4 Antioxidant and antimicrobial activity of the hydromethanolic extract and infusion obtained from wild Fragaria vesca L. fruits and their correlation factor $\left(r^{2}\right)$ with the phenolic compounds families identified

\begin{tabular}{|c|c|c|c|c|c|c|c|c|c|}
\hline $\begin{array}{l}\text { Antioxidant activity } \mathrm{EC}_{50} \text { values } \\
\left(\mathrm{mg} \mathrm{mL}^{-1}\right)\end{array}$ & $\begin{array}{l}\text { Hydromethanolic } \\
\text { extracts }\end{array}$ & Infusions & $\begin{array}{l}\text { Student's } t \text {-test } \\
p \text {-value }\end{array}$ & \multicolumn{6}{|c|}{ Correlation factor $r^{2}$} \\
\hline DPPH scavenging activity & $164 \pm 4$ & $282 \pm 7$ & $<0.001$ & 0.9855 & 0.9892 & 0.9876 & 0.9812 & 0.9897 & 0.9905 \\
\hline $\begin{array}{l}\beta \text {-Carotene bleaching } \\
\text { inhibition }\end{array}$ & $28 \pm 2$ & $100 \pm 6$ & $<0.001$ & 0.9891 & 0.9819 & 0.9818 & 0.9736 & 0.9825 & 0.9843 \\
\hline TBARS inhibition & $9.2 \pm 0.2$ & $33 \pm 1$ & $<0.001$ & 0.9916 & 0.9954 & 0.9937 & 0.9873 & 0.9958 & 0.9966 \\
\hline
\end{tabular}

Antimicrobial activity MIC values $\left(\mathrm{mg} \mathrm{mL}^{-1}\right)$

Gram negative bacteria

Acinetobacter baumannii

Escherichia coli ESBL $1^{a}$

Escherichia coli ESBL $2^{a}$

Escherichia coli

Klebsiella pneumoniae

Klebsiella pneumoniae $\mathrm{ESBL}^{a}$

Morganella morganii

Pseudomonas aeruginosa

4
$1\left(47 \%{ }^{b}\right)$
$0.25\left(49 \%^{b}\right)$
0.5
1
$1\left(62 \%{ }^{b}\right)$
2
2

4
1
0.25
2
1
1
2
4

-
-
-
-
$=$
-

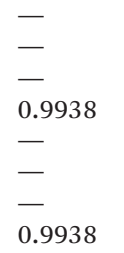

$$
\begin{aligned}
& - \\
& - \\
& 0.9976 \\
& - \\
& - \\
& 0.9976
\end{aligned}
$$

-
-
0.9959
-
-
0.9959

$\begin{array}{ll}- & - \\ - & - \\ - & - \\ 0.9895 & 0.998 \\ - & - \\ - & - \\ - & - \\ 0.9895 & 0.998\end{array}$

-
-
0.9989
-
-
$\overline{0}$
0.9989

Gram positive bacteria

Enterococcus faecalis

MRSA $^{a}$

Streptococcus agalactiae

$$
\begin{aligned}
& 2 \\
& 0.25\left(85 \%^{b}\right)
\end{aligned}
$$

2

0.25

$\mathrm{EC}_{50}$ values correspond to the sample concentration achieving $50 \%$ of antioxidant activity or 0.5 of absorbance in reducing power assay. MIC values correspond to the minimal sample concentration that inhibited the bacterial growth. TPA - total phenolic acids; TED - total ellagic acid derivatives; TF3O - total flavan-3-ols; TF - total flavonols; TPC - total phenolic compounds (non-anthocyanins); TA - total anthocyanins. ${ }^{a}$ Biofilm producers. ${ }^{b}$ Inhibition percentage of biofilm production.

(infusions) and/or nutraceuticals/pharmaceutical formulations (hydromethanolic extracts).

\section{Acknowledgements}

The authors are grateful to Fundação para a Ciência e a Tecnologia (FCT, Portugal) for the financial support to CIMO (strategic project UID/AGR/00690/2013) and to REQUIMTE (national funds and co-financed by FEDER, under the Partnership Agreement PT2020), and to the ALIMNOVA research group (UCM-GR3/14). L. Barros and M. I. Dias thank FCT for their grants (SFRH/BPD/107855/2015 and SFRH/BD/ $84485 / 2012$, respectively). The GIP-USAL is financially supported by the Spanish Government through the project BFU2012-35228. The authors also thank the Local Health Unit of Bragança and Hospital Center of Trás-os-Montes and AltoDouro, Vila Real, Portugal for the microorganisms.

\section{References}

1 E. Kaczmarska, J. Gawroński, M. Dyduch-siemińska and A. Najda, Turk. J. Agric. For., 2015, 39, 394-402.

2 P. K. Mishra, R. B. Ram and N. Kumar, Turk. J. Agric. For., 2015, 39, 451-458.

3 A. Ipek, K. Yılmaz, P. Sıkıcı, N. A. Tangu, A. T. Oz, M. Bayraktar, M. Ipek and H. Gulen, Biochem. Genet., 2016, 54, 313-325.
4 S. Doumett, D. Fibbi, A. Cincinelli, E. Giordani, S. Nin and M. Del, Food. Res. Int., 2011, 44, 1209-1216.

5 I. Gülçin, Arch. Toxicol., 2012, 86, 345-391.

6 P. W. Taylor, Int. J. Antimicrob. Agents, 2013, 42, 195-201.

7 M. Carocho, P. Morales and I. C. F. R. Ferreira, Trends Food Sci. Technol., 2015, 45, 284-295.

8 S. Castroviejo, C. Aedo, S. Cirujano, M. Laínz, P. Montserrat, R. Morales, F. Muñoz Garmendia, C. Navarro, J. Paiva and C. Soriano, Flora Ibérica 6, CSIC, Madrid, 1998.

9 G. Caruso, G. Villari, G. Melchionna and S. Conti, Sci. Hortic., 2011, 129, 479-485.

10 I. Pawlaczyk, M. Lewik-Tsirigotis, P. Capek, M. Matulová, V. Sasinková, P. Dabrowski, W. Witkiewicz and R. Gancarz, Carbohydr. Polym., 2013, 92, 741-750.

11 J. Thill, S. Miosic, T. P. Gotame, M. Mikulic-Petkovsek, C. Gosch, R. Veberic, A. Preuss, W. Schwab, F. Stampar, K. Stich and H. Halbwirth, Plant Physiol. Biochem., 2013, 72, 72-78.

12 I. Pawlaczyk, L. Czerchawski, W. Pilecki, E. Lamer-Zarawska and R. Gancarz, Carbohydr. Polym., 2009, 77, 568575.

13 K. Šavikin, G. Zdunić, N. Menković, J. Živković, N. Ćujić, M. Tereščenko and D. Bigović, J. Ethnopharmacol., 2013, 146, 803-810.

14 M. C. Houston, Altern. Ther. Health Med., 2013, 19, 32-49.

15 M. Blanch, O. Goñi, M. T. Sanchez-ballesta, M. I. Escribano and C. Merodio, Food Chem., 2012, 134, 912-919. 
16 J. D. J. Ornelas-Paz, E. M. Yahia, N. Ramírez-Bustamante, J. D. Pérez-Martínez, M. D. P. Escalante-Minakata, V. Ibarra-Junquera, C. Acosta-Muñiz, V. Guerrero-Prieto and E. Ochoa-Reyes, Food Chem., 2013, 138, 372-381.

17 P. Ramulu and P. U. Rao, J. Food Compos. Anal., 2003, 16, 677-685.

18 M. N. Clifford, J. Sci. Food Agric., 2000, 80, 1126-1137.

19 Y. Zheng, S. Y. Wang, C. Y. Wang and W. Zheng, LWT - Food Sci. Technol., 2007, 40, 49-57.

20 M. da Silva Pinto, F. M. Lajolo and M. I. Genovese, Food Chem., 2008, 107, 1629-1635.

21 M. J. Simirgiotis and G. Schmeda-Hirschmann, J. Food Compos. Anal., 2010, 23, 545-553.

22 K. Aaby, S. Mazur, A. Nes and G. Skrede, Food Chem., 2012, 132, 86-97.

23 M. Del Bubba, L. Checchini, U. Chiuminatto, S. Doumett, D. Fibbi and E. Giordani, J. Mass Spectrom., 2012, 47, 12071220.

24 M. Gasperotti, D. Masuero, G. Guella, L. Palmieri, P. Martinatti, E. Pojer, F. Mattivi and U. Vrhovsek, J. Agric. Food Chem., 2013, 61, 8597-8607.

25 J. Sun, X. Liu, T. Yang, J. Slovin and P. Chen, Food Chem., 2014, 146, 289-298.

26 Y. Nuñez-mancilla, M. Pérez-won, E. Uribe, A. Vega-gálvez and K. Di, LWT - Food Sci. Technol., 2013, 52, 151-156.

27 J. Cheel, C. Theoduloz, J. A. Rodríguez, P. D. S. Caligari and G. Schmeda-Hirschmann, Food Chem., 2007, 102, 36-44.

28 Đ. Sofija, I. Arsi, G. Markovi, Z. Jelena and Z. Ana, Food Chem., 2014, 52, 519-527.

29 W. Xu, H. Peng, T. Yang, B. Whitaker, L. Huang, J. Sun and P. Chen, Plant Physiol. Biochem., 2014, 82, 289-298.

30 AOAC, Official methods of analysis of AOAC international, AOAC International, Gaithersburg, 18th edn, 2005.

31 G. W. Latimer, Official methods of analysis of AOAC international, Gaithersburg, 18th edn, 2012.

32 Regulation (EC) No 1169/2011, Off. J. Eur. Union, 2011, 18-63.

33 L. Barros, E. Pereira, R. C. Calhelha, M. Dueñas, A. M. Carvalho, C. Santos-Buelga and I. C. F. R. Ferreira, J. Funct. Foods, 2013, 5, 1732-1740.
34 M. I. Dias, L. Barros, P. Morales, M. C. Sánchez-Mata, M. B. P. P. Oliveira and I. C. F. Ferreira, LWT - Food Sci. Technol., 2015, 62, 32-38.

35 L. Barros, C. Pereira and I. C. F. R. Ferreira, Food Anal. Methods, 2013, 6, 309-316.

36 B. M. Ruiz-Rodríguez, P. Morales, V. Fernández-Ruiz, M. C. Sánchez-Mata, M. Cãmara, C. Díez-Marqués, M. Pardo-de-Santayana, M. Molina and J. Tardío, Food Res. Int., 2011, 44, 1244-1253.

37 M. C. Sanchez-Mata, Efecto del almacenamiento en atmosferas controladas sobre el valor nutritivo de judias verdes (Phaseolus vulgaris L., cv. Perona), 2000.

38 P. Morales, V. Fernéndez-Ruiz, M. C. Sánchez-Mata, M. Cãmara and J. Tardío, Food Anal. Methods, 2014, 8, 302311.

39 R. Guimarães, L. Barros, M. Dueñas, A. M. Carvalho, M. J. R. P. Queiroz, C. Santos-Buelga and I. C. F. R. Ferreira, Food Chem., 2013, 141, 3721-3730.

40 M. I. Dias, L. Barros, M. B. P. P. Oliveira, C. Santos-Buelga and I. C. F. R. Ferreira, Ind. Crops Prod., 2015, 63, 125-132.

41 M. I. Dias, L. Barros, I. P. Fernandes, G. Ruphuy, M. B. P. P. Oliveira, C. Santos-Buelga, M. F. Barreiro and I. C. F. R. Ferreira, J. Funct. Foods, 2015, 16, 243-255.

42 M. Alves, I. Ferreira, I. Lourenço, E. Costa, A. Martins and M. Pintado, Pathogens, 2014, 3, 667-679.

43 Regulation (EC) No 1924/2006, EU- Lex, 2006, 9-25.

44 K. Pytlakowska, A. Kita, P. Janoska, M. Połowniak and V. Kozik, Food Chem., 2012, 135, 494-501.

45 V. Fajardo, E. Alonso-Aperte and G. Varela-Moreiras, Food Chem., 2015, 169, 283-288.

46 S. J. Britz, P. V. V. Prasad, R. A. Moreau, L. H. Allen, D. F. Kremer and K. J. Boote, J. Agric. Food Chem., 2007, 55, 7559-7565.

47 J. Liberal, G. Costa, A. Carmo, R. Vitorino, C. Marques, M. R. Domingues, P. Domingues, A. C. Gonçalves, R. Alves, A. B. Sarmento-Ribeiro, H. Girão, M. T. Cruz and M. T. Batista, Arabian J. Chem., 2015, DOI: 10.1016/ j.arabjc.2015.11.014.

48 M. J. Alves, H. J. C. Froufe, A. F. T. Costa, A. F. Santos, L. G. Oliveira, S. R. M. Osório, R. M. V. Abreu, M. Pintado and I. C. F. R. Ferreira, Molecules, 2014, 19, 1672-1684. 